\title{
Short communication: Effects of body fat mobilization on macrophage infiltration in adipose tissue of early lactation dairy cows
}

\author{
Jenne De Koster, ${ }^{*}$ Clarissa Strieder-Barboza, ${ }^{*}$ Jonas de Souza, $†$ Adam L. Lock, $†$ and G. Andres Contreras ${ }^{* 1}$ \\ *Department of Large Animal Clinical Sciences, and \\ †Department of Animal Science, Michigan State University, East Lansing MI 48824
}

\begin{abstract}
Intense lipolysis triggers an inflammatory response within adipose tissue characterized by adipose tissue macrophage (ATM) infiltration; however, the mechanisms triggering this process are poorly characterized in transition dairy cows. The aim of this study was to determine the association between ATM infiltration and body fat mobilization in the transition period, markers of excessive lipolysis, and adipose tissue expression of genes related to chemotactic and inflammatory responses. Subcutaneous adipose tissue samples were taken from the tailhead of 9 multiparous Holstein cows, $27 \pm 2.2 \mathrm{~d}$ (far-off) and $10 \pm 1.5 \mathrm{~d}$ (close-up) before and $9 \pm 0.3 \mathrm{~d}$ after calving (fresh). Blood samples were collected by coccygeal venipuncture $2 \mathrm{~h}$ before adipose sample collections. Body condition score (BCS) was assessed independently by 3 experienced technicians at every time point. Based on BCS loss intensity between the close-up and fresh period, cows were divided into 2 groups: low BCS loss (LBCSL, change in BCS $<0.25$ units, $\mathrm{n}=5$ ) and high BCS loss (HBCSL, change in BCS $>0.25$ units, $\mathrm{n}=4$ ). Although none of the LBCSL cows had a health event, all cows in the HBCSL group suffered from one or more clinical disorder (retained placenta, milk fever, or ketosis) in the transition period. The number of ATM was determined by immunohistochemistry, and expression of selected chemotactic and inflammatory genes was determined by reversetranscription quantitative real-time PCR in subcutaneous adipose tissue samples. The proportion of ATM in subcutaneous adipose tissue increased in HBCSL during the postpartum period. The proportion of ATM was not associated with serum $\beta$-hydroxybutyrate or free fatty acid concentrations on the day of adipose tissue collection. The ATM infiltration in the fresh period was associated with local expression of the chemotactic genes, C-C motif chemokine ligand 22 (CCL22), osteo-
\end{abstract}

Received December 19, 2017.

Accepted April 24, 2018.

${ }^{1}$ Corresponding author: contre28@msu.edu pontin $(S P P 1)$, and the receptor for SPP1, cluster of differentiation 44 (CD44). This supports a potential chemotactic role of CCL22 and SPP1 for ATM in bovine adipose tissue. None of the genes encoding pro- or antiinflammatory mediators, tumor necrosis factor $(T N F)$, IL6, and IL10 were associated with the proportion of ATM. Our results indicate that ATM infiltration of subcutaneous adipose tissue is associated with body fat mobilization in early-lactation dairy cows and supports a role for ATM in the adaptation of adipose tissues to the metabolic challenges of the transition period.

Key words: adipose tissue remodelling, adipose tissue macrophage, immune response, transition cow

\section{Short Communication}

Adipose tissue (AT) is the main energy reserve in the body of cows. It is not uncommon that in the first weeks after calving, 30\% to $50 \%$ of the triglycerides stored in adipocytes are broken down and their fatty acids (FA) mobilized (McNamara, 1991; von Soosten et al., 2011). Because FA are an important energy source for different tissues, their mobilization is a physiological mechanism to support the energy needs of lactation, thereby preserving glucose to be used for milk production (De Koster and Opsomer, 2013). Periparturient FA mobilization intensity is determined by the balance between lipogenesis and lipolysis within adipocytes and is mainly regulated by catecholamines, growth hormone, and insulin (Roche et al., 2009).

In humans and rodents, intense lipolysis triggers an inflammatory response within AT. Part of this inflammatory response is mediated by AT macrophages (ATM) that reside or infiltrate the adipose organ (Hotamisligil, 2006). These inflammatory changes within AT influence whole-body metabolic function, and when chronic, may lead to type 2 diabetes mellitus and cardiovascular disease (Cornier et al., 2008). In dairy cows, where adipocyte volume decreases in the first weeks after calving due to increased lipolysis and decreased lipogenesis, inflammatory changes develop in AT (Contreras et al., 2017b). Different research groups 
have documented ATM infiltration in adipose depots of dairy cows around parturition and during early lactation using immunohistochemistry (Akter et al., 2012), flow cytometry (Clark, 2014; Contreras et al., 2015), and microRNA markers (Vailati-Riboni et al., 2017). The ATM were abundantly present in AT from cows suffering from abomasal displacement and ketosis, 2 conditions that are associated with excessive lipolysis (Contreras et al., 2015). In the same study, expression of several pro-inflammatory genes, tumor necrosis factor $(T N F), I L 6$, and C-C motif chemokine ligand 2 (CCL2), provided further evidence for an important interrelationship between lipolysis and inflammatory pathways within AT of transition cows (Contreras et al., 2015). We hypothesized that lipolysis and inflammation in AT are involved in a vicious cycle where ATM infiltration is increased by FA mobilization and production of inflammatory mediators by ATM further exacerbates lipolysis (Contreras et al., 2017b). To evaluate the crosstalk between lipolysis and inflammatory events within AT, the aim of our current study was to quantify ATM infiltration and adipose expression of selected chemotactic and inflammatory genes in subcutaneous AT from dairy cows during the transition period.

All animal procedures were approved by the Michigan State University Animal Care and Use Committee. A convenience sample of 9 multiparous (2.6 \pm 0.73 lactations, mean \pm SD) Holstein dairy cows from the Michigan State University Dairy Teaching and Research Center (East Lansing) were enrolled in the study. Cows were nonlactating and pregnant $(>235 \mathrm{~d}$ of gestation) and housed in tiestall barns bedded with sawdust. Cows were fed a dry period TMR diet from 60 to $21 \mathrm{~d}$ prepartum, a close-up diet from $21 \mathrm{~d}$ until calving and an early-lactation diet following parturition (Supplemental Table S1; https://doi.org/10.3168/ jds.2017-14318).

Blood and subcutaneous AT samples were taken at $27 \pm 2.2 \mathrm{~d}$ (far-off) and $10 \pm 1.5 \mathrm{~d}$ (close-up) before calving and $9 \pm 0.3 \mathrm{~d}$ after parturition (fresh). The AT samples were collected from the tailhead using minimally invasive surgical techniques as previously described (Contreras et al., 2017a). Three to five grams of subcutaneous AT were obtained from the surgical site. Subsequent biopsies were obtained from opposite sites. Immediately after sampling, a part of the AT sample was fixed in $4 \%$ formaldehyde for $24 \mathrm{~h}$, a part was snap frozen in liquid nitrogen and stored at $-80^{\circ} \mathrm{C}$ until further analysis, and a part was collected in RNA Later (Life Technologies, Carlsbad, CA), snap frozen in liquid nitrogen, and stored at $-80^{\circ} \mathrm{C}$ for gene expression analysis.
Blood samples were collected $2 \mathrm{~h}$ before adipose sample collections via coccygeal venipuncture using uncoated serum collection tubes, centrifuged for 20 min at $3,000 \times g\left(15^{\circ} \mathrm{C}\right)$ for serum fraction collection, and stored at $-80^{\circ} \mathrm{C}$ until further analysis. Serum concentrations of free fatty acids (FFA) and BHB were determined as described in Contreras et al. (2017a).

Body condition score of the cows was assessed at every sampling by 3 experienced technicians using a 5 -point scale with 0.25 -point increments according to Wildman et al. (1982). Cows were divided into 2 groups based on the change in BCS between the close-up and fresh period: low BCS loss (LBCSL, change in BCS $<0.25$ units, $\mathrm{n}=5$ ) and high BCS loss (HBCSL, change in BCS $>0.25$ units, $\mathrm{n}=4$ ). During the experiment, cows were monitored and treated for health disorders by farm personnel. Ketotic cows were diagnosed by depressed attitude, decreased feed intake, and decreased milk production, and the presence of moderate $(40 \mathrm{mg} /$ $\mathrm{dL})$ to large $(80$ to $160 \mathrm{mg} / \mathrm{dL}$ ) urinary acetoacetate concentrations detected by Ketostix (Bayer Corp., Elkhart, IN). Retained placenta was diagnosed by its attachment to the uterus for longer than $12 \mathrm{~h}$ after calving. Milk fever was diagnosed by clinical signs such as recumbency, muscle tremors, unsteadiness, cool extremities, and depression.

Immunohistochemistry was carried out as described by Contreras et al. (2015). Sections $(5 \mu \mathrm{m})$ of formalinfixed AT samples were stained with a mouse monoclonal antibody to detect bovine CD172a (1:100; DH59B, Washington State University Monoclonal Antibody Center, Pullman). Positive (bovine spleen) and negative controls were included. Sections were counterstained with hematoxylin, and CD172a-positive cells were detected using an Olympus BX-40 microscope (Olympus, Center Valley, PA). This anti-bovine CD172a antibody has been used previously to detect ATM using immunohistochemistry and flow cytometry in different studies, and has proven to be consistent in the detection of ATM (Contreras et al., 2015, 2016). For this study, 500 adipocytes were counted and the number of CD172apositive cells detected while counting these adipocytes was used as a measure of macrophage infiltration into AT. Although CD172a is expressed by myeloid cells including monocytes, macrophages, and dendritic cells, and by neuronal cells (Ring et al., 2017), the proportion of dendritic cells and neuronal cells in AT is lower compared with the number of macrophages and monocytes (Ampem et al., 2016); therefore, for our statistical analyses, we defined ATM as CD172a-positive cells. The proportion of ATM was calculated as the number of CD172a-positive cells divided by 500 and given as a percentage. 
Table 1. Proportion of adipose tissue macrophages (ATM), BCS, serum free fatty acid (FFA), and BHB concentrations during the far-off, closeup, and fresh periods in dairy cows that lost $<0.25$ units of BCS (low BCS loss, LBCSL, $\mathrm{n}=5$ ) or cows that lost $>0.25$ units of BCS (high BCS loss, HBCSL, $\mathrm{n}=4$ ) between the close-up and fresh periods

\begin{tabular}{|c|c|c|c|c|c|c|c|c|c|c|}
\hline Item & \multicolumn{2}{|c|}{ Far-off } & \multicolumn{2}{|c|}{ Close-up } & \multicolumn{2}{|c|}{ Fresh } & $\mathrm{SEM}^{1}$ & \multicolumn{3}{|c|}{$P$-value ${ }^{2}$} \\
\hline Proportion of $\mathrm{ATM}^{3}(\%)$ & $1.24^{\mathrm{a}}$ & $1.85^{\mathrm{a}}$ & $2.72^{\mathrm{ab}}$ & $1.75^{\mathrm{a}}$ & $1.24^{\mathrm{a}}$ & $5.50^{\mathrm{b}}$ & 1.17 & $<0.05$ & $<0.05$ & $<0.001$ \\
\hline $\mathrm{BCS}^{4}$ & $3.42^{\mathrm{A}}$ & $3.90^{\mathrm{B}}$ & $3.40^{\mathrm{A}}$ & $3.83^{\mathrm{A}}$ & $3.27^{\mathrm{A}}$ & $3.40^{\mathrm{A}}$ & 0.19 & $<0.0001$ & 0.12 & $<0.001$ \\
\hline FFA $(\mathrm{mEq} / \mathrm{L})$ & $0.27^{\mathrm{a}}$ & $0.31^{\mathrm{a}}$ & $0.37^{\mathrm{a}}$ & $0.34^{\mathrm{a}}$ & $0.93^{\mathrm{b}}$ & $1.07^{\mathrm{b}}$ & 0.15 & $<0.0001$ & 0.67 & NS \\
\hline $\mathrm{BHB}(\mathrm{mmol} / \mathrm{L})$ & $0.48^{\mathrm{a}}$ & $0.49^{\mathrm{a}}$ & $0.49^{\mathrm{a}}$ & $0.44^{\mathrm{a}}$ & $2.43^{\mathrm{b}}$ & $2.59^{\mathrm{b}}$ & 0.74 & $<0.0001$ & 0.95 & NS \\
\hline
\end{tabular}

\footnotetext{
${ }^{\mathrm{a}, \mathrm{b}}$ Group means within a row with a different lowercase superscript differ $(P<0.05)$.

${ }^{\mathrm{A}, \mathrm{B}}$ Group means within the same period with a different uppercase superscript differ $(P<0.05)$.

${ }^{1} \mathrm{SEM}=$ greatest standard error of the mean.

${ }^{2} P$-values of the linear mixed model.

${ }^{3} \mathrm{~A}$ trend was observed for a difference between LBCSL in the close-up period and HBCSL in the fresh period $(P=0.06)$.

${ }^{4} \mathrm{~A}$ trend was observed for a difference between LBCSL and HBCSL in the close-up period $(P=0.06)$.
}

The AT RNA extraction, purification, conversion to cDNA, and quantitative PCR analysis were performed as described previously (Contreras et al., 2016). The quantitative PCR assays were conducted for C-C motif chemokine ligand 2 or monocyte chemoattractant protein 1 (CCL2), $\mathrm{C}-\mathrm{C}$ motif chemokine ligand 22 (CCL22), cluster of differentiation $44(C D 44)$, cluster of differentiation 68 (CD68), eukaryotic translation initiation factor 3 subunit $\mathrm{K}$ (EIF3K), IL10, IL6, ribosomal protein S9 (RPS9), signal-regulatory protein a $(S I R$ $P A)$, secreted phosphoprotein 1 or osteopontin (SPP1), and tumor necrosis factor $\alpha(T N F$; Supplemental Table S2; https://doi.org/10.3168/jds.2017-14318). The most stable reference genes, RPS9 and EIF3K, were selected using geNorm (Vandesompele et al., 2002). The quantification cycle values were converted to normalized relative gene expression as described by Hellemans et al. (2007).

Statistical analyses were performed in $\mathrm{R}$ ( $\mathrm{R}$ Core Team, 2017). Results are presented as mean \pm standard error of the mean unless otherwise stated. Normality of the variables was checked, and serum BHB and FFA concentrations and gene expression data were naturallogarithm transformed to yield a normal distribution. To determine the effects on BCS, FFA, BHB, and proportion of ATM, a mixed effect linear model was built with BCS, FFA, BHB, or proportion of ATM as dependent variable, period, BCS group, and the interaction between period and BCS group included as independent variables. Period was included as a repeated observation within the random factor cow. Pairwise comparisons between different groups were done using the Tukey's post hoc test. Residuals of every model were checked and found to be normally distributed. Interaction terms were removed from the model if not significant $(P>0.05)$. To determine the relationship between the proportion of ATM and the metabolite concentration or gene expression, Spearman correlation coefficients were calculated for the far-off, close-up, and fresh period. Significance and tendency were declared at $P<0.05$ and $0.05<P<0.10$, respectively.

Animals in the LBCSL group lost $0.13 \pm 0.03$ units of BCS between the close-up and fresh period, whereas animals in the HBCSL group lost $0.43 \pm 0.04$ units of BCS during that timeframe $(P<0.001$, Table 1$)$. During the postpartum period, cows in the LBCSL group remained healthy, whereas the 4 cows in the HBCSL were diagnosed to suffer from one or more clinical disorder (3 cows were diagnosed with ketosis, 2 cows were diagnosed with retained placenta, and 1 cow was diagnosed with milk fever).

Serum FFA and BHB increased in the postpartum period. However, no differences were detected in serum BHB and FFA between LBCSL and HBCSL cows. Because lipolysis intensity has been linked to ATM infiltration, we evaluated the infiltration intensity of ATM in subcutaneous AT samples. In all histological sections, CD172a-positive cells could be detected. The proportion of ATM was greater in AT samples from HBCSL cows during the fresh period compared with all other samples (Figure 1, Table 1). The proportion of ATM was not associated with serum BHB or FFA concentration (Table 2). In contrast, a positive association was observed between the proportion of ATM and expression of CCL22 $(P<0.05), C D 44(P<0.05), S P P 1(P$ $<0.05)$, and $C D 68(P<0.05)$ during the fresh period. The expression of pro- and anti-inflammatory genes, TNF, IL6, and IL10, in AT was not associated with the proportion of ATM (Table 2). Normally, BCS loss in the postpartum period is 0.5 to 1 point from calving until its nadir at around 40 to 60 DIM. However, in the short observation period of this study $(-27$ to $9 \mathrm{~d}$ relative to calving) HBCSL lost almost 0.5 BCS points compared with the low BCS loss observed in LBCSL. 


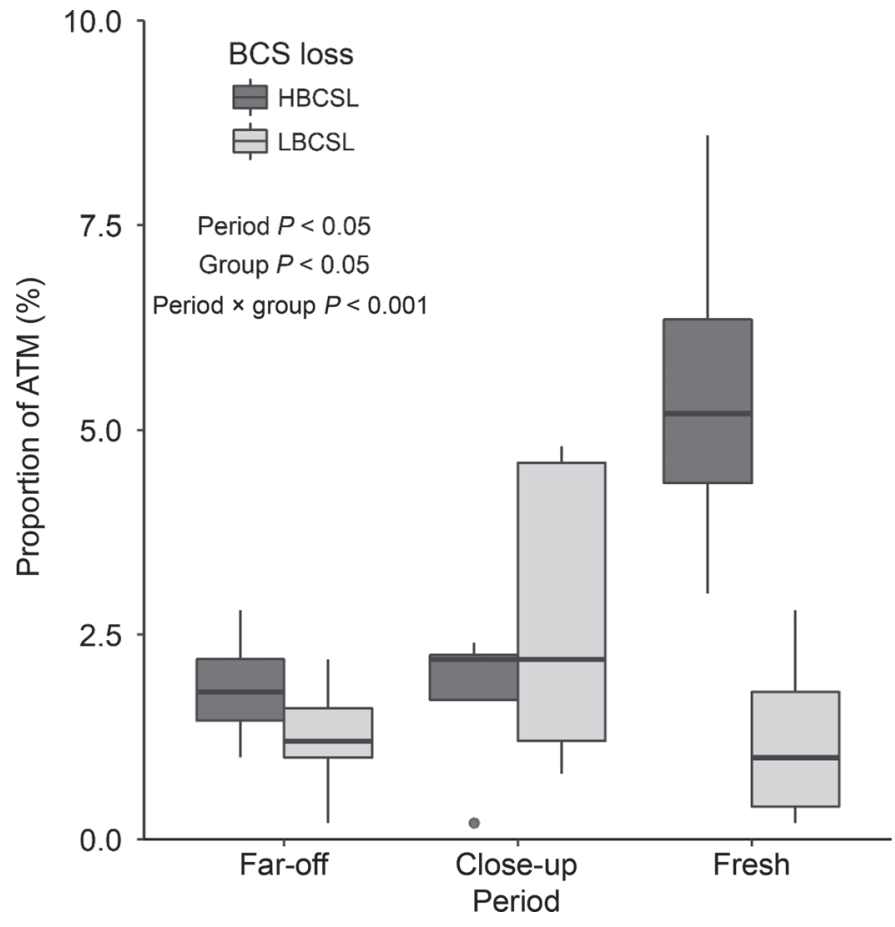

Figure 1. Proportion of adipose tissue macrophages (ATM) in subcutaneous adipose tissue samples taken from the tailhead of dairy cows during the far-off ( $27 \pm 2.2 \mathrm{~d}$ before calving), close-up (10 $\pm 1.5 \mathrm{~d}$ before calving), and fresh ( $9 \pm 0.3 \mathrm{~d}$ after calving) periods in cows that lost $<0.25$ units of BCS (low BCS loss, LBCSL, $\mathrm{n}=5$ ) or cows that lost $>0.25$ units of BCS (high BCS loss, HBCSL, $\mathrm{n}=4$ ) between the close-up and fresh periods. $P$-values of the linear mixed model for the effect of period, BCS group, and the interaction between period and BCS group on the proportion of ATM. Horizontal line is the median; boxes represent the 25th and 75th percentiles; upper and lower whiskers extend to the largest or smallest value no further than $1.5 \times$ the interquartile range; data beyond the end of the whiskers are plotted individually as dots.

Table 2. Spearman correlation coefficients between the proportion of adipose tissue macrophages and the serum BHB and free fatty acid (FFA) concentrations, and the gene expression of CCL2, SPP1, CD44, CCL22, TNF, IL6, IL10, CD68, and SIRPA in subcutaneous adipose tissue from the tailhead of dairy cows during the far-off $(27 \pm 2.2 \mathrm{~d}$ before calving), close-up $(10 \pm 1.5 \mathrm{~d}$ before calving $)$, and fresh $(9 \pm$ $0.3 \mathrm{~d}$ after calving) periods $(\mathrm{n}=9)$

\begin{tabular}{lrcc}
\hline & \multicolumn{3}{c}{ Spearman correlation coefficient } \\
\cline { 2 - 4 } Item & Far-off & Close-up & $\begin{array}{c}\text { Early } \\
\text { lactation }\end{array}$ \\
\hline FFA (mEq/L) & -0.22 & -0.56 & 0.02 \\
BHB (mmol/L) & -0.02 & -0.44 & 0.07 \\
CCL2 & 0.34 & -0.36 & 0.48 \\
SPP1 & -0.20 & $-0.66 \dagger$ & $0.80^{*}$ \\
CD44 & 0.14 & -0.34 & $0.73^{*}$ \\
CCL22 & 0.29 & -0.29 & $0.73^{*}$ \\
TNF & -0.17 & -0.07 & 0.47 \\
IL6 & 0.29 & -0.41 & 0.42 \\
IL10 & 0.12 & -0.27 & 0.47 \\
CD68 & -0.13 & -0.53 & $0.72^{*}$ \\
SIRPA & 0.34 & -0.03 & 0.18 \\
\hline
\end{tabular}

${ }^{*} P<0.05 ; \dagger 0.05<P<0.1$.
This reduction in BCS may have predisposed HBCSL cows to disease as it was observed in epidemiological studies (Chebel et al., 2018).

Macrophages are the predominant immune cell type in AT of cattle (Ampem et al., 2016). Increased infiltration of these cells into AT of transition cows has been demonstrated by immunohistochemistry (Akter et al., 2012) and microRNA markers (Vailati-Riboni et al., 2017). The ATM infiltration appears to be enhanced in cows with displaced abomasum and ketosis (Contreras et al., 2015). Similarly, in the present study the proportion of ATM in subcutaneous AT increased considerably in HBCSL cows that suffered from clinical disorders in the postpartum period. However, a limitation of our approach is that we cannot determine if the increased number of ATM is due to BCS loss or clinical diseases in the HBCSL group and whether the clinical disorders are a cause or consequence of BCS loss.

In rodent models of induced lipolysis, macrophages infiltrate AT in response to increased release of FFA from adipocytes (Kosteli et al., 2010). In conditions associated with enhanced FFA mobilization in dairy cows (metabolic diseases, feed restriction, and postpartum cows), the number of ATM and the expression of genes associated with ATM infiltration were increased compared with control cows (Contreras et al., 2015, 2016; Vailati-Riboni et al., 2017). Unexpectedly, the infiltration of ATM in our current study was not associated with serum FFA or BHB concentrations. This lack of association may be explained by different factors. Serum FFA concentrations typically peak during the first days after calving, whereas BHB concentrations peak later in the postpartum period (McCarthy et al., 2015). Our samples were taken $10 \mathrm{~d}$ after calving, which may be too late to capture the FFA peak. Additionally, the infiltration of ATM may be induced in the early postpartum period coinciding with the FFA peak (Kosteli et al., 2010). When FFA concentrations decrease afterward, ATM remain in AT to fulfill their function. Serum FFA concentration reflects the mobilization of fat from all adipose depots and this may differ between different adipose depot locations (De Koster et al., 2016). Possibly, the infiltration of ATM may be more related to the local release of adipokines and FFA within different adipose depots. Variability in the utilization of FFA and BHB by different tissues may also affect circulating concentrations of both metabolites and explain the lack of association.

Macrophage infiltration into AT is initiated by secretion of chemotactic proteins (Hill et al., 2014; Kahles et al., 2014). In the current study, postpartum ATM infiltration was associated with the gene expression of the chemotactic proteins CCL22 and SPP1 (encoding osteopontin) and the osteopontin receptor, $C D 44$. 
Previously, CCL2 transcription was linked with ATM infiltration in AT of dairy cows (Contreras et al., 2015). However, the association between ATM and the $C D 44$ and SPP1 is novel. Based on the results of the present study, we hypothesize that $\mathrm{C}-\mathrm{C}$ motif chemokine ligand 22 (CCL22) and osteopontin (SPP1) stimulate the infiltration of ATM in AT of fresh cows.

The function of ATM is to remove dead adipocytes, lipotoxic products, and stimulate adipogenesis (Boutens and Stienstra, 2016). Generally, ATM have 2 phenotypes. The M1 or classically activated ATM are pro-inflammatory and secrete pro-inflammatory mediators (IL6 and TNF) to induce local and systemic inflammation. The M2 or alternatively activated ATM are anti-inflammatory (IL10 secretion), restore tissue damage, resolve ongoing inflammation, and stimulate adipogenesis to buffer excess FA (Hill et al., 2014). Depending on the AT environment, ATM can be polarized toward one of these 2 extremes. In our study, the gene expression of pro- and anti-inflammatory genes was not associated with the proportion of ATM following a similar pattern to that observed in ATM populations in feed-restricted cows (Contreras et al., 2016). However, changes in the phenotype of ATM may be associated with the extended periods of intense lipolysis and possibly subclinical and clinical ketosis as demonstrated in Contreras et al. (2015) where pro-inflammatory polarization of ATM was described in cases of abomasal displacement with concurrent ketosis. Reasons for the conflicting results are unclear but may be due to the relatively small sample size in the present study and the fact that gene expression was measured at the AT level, which comprises the mRNA expression of all the cells within AT, being preadipocytes, fibroblasts, endothelial cells, T lymphocytes, and macrophages (Heilbronn and Campbell, 2008). Additionally, there may be differences between adipose depots. The association between pro-inflammatory gene expression and the infiltration of ATM was stronger in omental compared with subcutaneous AT (Contreras et al., 2015). Potentially, at the moment of biopsy, there could have been a balance between the degree of polarization of ATM between M1 and M2. Therefore, further research is needed to identify the phenotype of the ATM that infiltrate bovine $\mathrm{AT}$ and its effect on the metabolic function of AT during periods of increased lipolysis such as the transition period.

We expected that the gene expression of SIRPA and $C D 68$ would be related to the number of ATM. The SIRPA codes for CD172a, the protein used to detect the ATM. Lack of association between ATM and SIRPA may be due to the asynchrony between gene expression and protein synthesis, a well-known limitation of gene expression studies (Ly et al., 2014).
A lysosomal-associated membrane protein, CD68, is a general macrophage marker and was associated with the proportion of ATM in the fresh period of our study. We speculate that the expression of $C D 68$ could be a measure for ATM infiltration in bovine AT.

Our results indicate that ATM infiltration was associated with the expression of genes related to chemotaxis of immune cells in AT: CCL22, CD44, and SPP1, supporting a chemotactic role of C-C motif chemokine ligand 22 and osteopontin for ATM in bovine AT. The gene expression of pro- and anti-inflammatory genes, TNF, IL6, and IL10, was not associated with the number of ATM. Although immunohistochemical analysis of CD172a-positive cells in AT alone cannot distinguish between monocytes and mature ATM, it is a good proxy of the trafficking patterns of mononuclear cells into the adipose organ. Monocyte migration into AT and their maturation into macrophages is strongly dependent on CCL2 chemotactic signaling (Oh et al., 2012). The present study provides evidence of intense ATM trafficking in the adaptation of AT to the metabolic challenges of the transition period. However, more research is needed to determine the function of these ATM and to determine the triggering events for the infiltration of macrophages into AT of dairy cows.

\section{ACKNOWLEDGMENTS}

This research was funded by USDA-National Institute of Food and Agriculture (Washington, DC) grants 2014-68004-21972 and 2015-67015-23207, Michigan Alliance for Animal Agriculture, the Department of Large Animal Clinical Sciences (East Lansing, MI), and Global Agri-Trade Corporation (Rancho Dominguez, CA). The authors are grateful to Whitney James, Kyan Thelen, Courtney L. Preseault, Laura Gualdron, William Raphael, and the staff at the Michigan State University Field Laboratory (East Lansing) for animal care and technical assistance.

\section{REFERENCES}

Akter, S. H., S. Häussler, D. Germeroth, D. von Soosten, S. Dänicke, K. H. Südekum, and H. Sauerwein. 2012. Immunohistochemical characterization of phagocytic immune cell infiltration into different adipose tissue depots of dairy cows during early lactation. J. Dairy Sci. 95:3032-3044.

Ampem, G., H. Azegrouz, A. Bacsadi, L. Balogh, S. Schmidt, J. Thuroczy, and T. Roszer. 2016. Adipose tissue macrophages in nonrodent mammals: A comparative study. Cell Tissue Res. 363:461478.

Boutens, L., and R. Stienstra. 2016. Adipose tissue macrophages: Going off track during obesity. Diabetologia 59:879-894.

Chebel, R. C., L. G. D. Mendonca, and P. S. Baruselli. 2018. Association between body condition score change during the dry period and postpartum health and performance. J. Dairy Sci.101:45954614. 
Clark, M. 2014. Characterization of Adiposity associated changes in the adipose tissue of peripartal dairy cows. BS Thesis. University of Delaware, Newark.

Contreras, G. A., E. Kabara, J. Brester, L. Neuder, and M. Kiupel. 2015. Macrophage infiltration in the omental and subcutaneous adipose tissues of dairy cows with displaced abomasum. J. Dairy Sci. 98:6176-6187.

Contreras, G. A., C. Strieder-Barboza, J. de Souza, J. Gandy, V. Mavangira, A. L. Lock, and L. M. Sordillo. 2017a. Periparturient lipolysis and oxylipid biosynthesis in bovine adipose tissues. PLoS One 12:e0188621.

Contreras, G. A., C. Strieder-Barboza, and W. Raphael. 2017b. Adipose tissue lipolysis and remodeling during the transition period of dairy cows. J. Anim. Sci. Biotechnol. 8:41-53.

Contreras, G. A., K. Thelen, S. E. Schmidt, C. Strieder-Barboza, C. L. Preseault, W. Raphael, M. Kiupel, J. Caron, and A. L. Lock. 2016. Adipose tissue remodeling in late-lactation dairy cows during feed-restriction-induced negative energy balance. J. Dairy Sci. 99:10009-10021.

Cornier, M. A., D. Dabelea, T. L. Hernandez, R. C. Lindstrom, A. J. Steig, N. R. Stob, R. E. Van Pelt, H. Wang, and R. H. Eckel. 2008. The metabolic syndrome. Endocr. Rev. 29:777-822.

De Koster, J., W. Van den Broeck, L. Hulpio, E. Claeys, M. Van Eetvelde, K. Hermans, M. Hostens, V. Fievez, and G. Opsomer. 2016. Influence of adipocyte size and adipose depot on the in vitro lipolytic activity and insulin sensitivity of adipose tissue in dairy cows at the end of the dry period. J. Dairy Sci. 99:2319-2328.

De Koster, J. D., and G. Opsomer. 2013. Insulin resistance in dairy cows. Vet. Clin. North Am. Food Anim. Pract. 29:299-322.

Heilbronn, L. K., and L. V. Campbell. 2008. Adipose tissue macrophages, low grade inflammation and insulin resistance in human obesity. Curr. Pharm. Des. 14:1225-1230.

Hellemans, J., G. Mortier, A. De Paepe, F. Speleman, and J. Vandesompele. 2007. qBase relative quantification framework and software for management and automated analysis of real-time quantitative PCR data. Genome Biol. 8:R19.

Hill, A. A., W. Reid Bolus, and A. H. Hasty. 2014. A decade of progress in adipose tissue macrophage biology. Immunol. Rev. 262:134-152.

Hotamisligil, G. S. 2006. Inflammation and metabolic disorders. Nature 444:860-867.

Kahles, F., H. M. Findeisen, and D. Bruemmer. 2014. Osteopontin: A novel regulator at the cross roads of inflammation, obesity and diabetes. Mol. Metab. 3:384-393.

Kosteli, A., E. Sugaru, G. Haemmerle, J. F. Martin, J. Lei, R. Zechner, and A. W. Ferrante Jr. 2010. Weight loss and lipolysis promote a dynamic immune response in murine adipose tissue. J. Clin. Invest. 120:3466-3479.
Ly, T., Y. Ahmad, A. Shlien, D. Soroka, A. Mills, M. J. Emanuele, M. R. Stratton, and A. I. Lamond. 2014. A proteomic chronology of gene expression through the cell cycle in human myeloid leukemia cells. eLife 3:e01630.

McCarthy, M. M., S. Mann, D. V. Nydam, T. R. Overton, and J. A. A. McArt. 2015. Short communication: Concentrations of nonesterified fatty acids and $\beta$-hydroxybutyrate in dairy cows are not well correlated during the transition period. J. Dairy Sci. 98:6284-6290.

McNamara, J. P. 1991. Regulation of adipose tissue metabolism in support of lactation. J. Dairy Sci. 74:706-719.

Oh, D. Y., H. Morinaga, S. Talukdar, E. J. Bae, and J. M. Olefsky. 2012. Increased macrophage migration into adipose tissue in obese mice. Diabetes 61:346-354.

$\mathrm{R}$ Core Team. 2017. R: A language and environment for statistical computing. R Foundation for Statistical Computing. Vienna, Austria.

Ring, N. G., D. Herndler-Brandstetter, K. Weiskopf, L. Shan, J.-P. Volkmer, B. M. George, M. Lietzenmayer, K. M. McKenna, T. J. Naik, A. McCarty, Y. Zheng, A. M. Ring, R. A. Flavell, and I. L. Weissman. 2017. Anti-SIRPa antibody immunotherapy enhances neutrophil and macrophage antitumor activity. Proc. Natl. Acad. Sci. USA 114:E10578-E10585.

Roche, J. R., N. C. Friggens, J. K. Kay, M. W. Fisher, K. J. Stafford, and D. P. Berry. 2009. Invited review: Body condition score and its association with dairy cow productivity, health, and welfare. J. Dairy Sci. 92:5769-5801.

Vailati-Riboni, M., G. Farina, F. Batistel, A. Heiser, M. D. Mitchell, M. A. Crookenden, C. G. Walker, J. K. Kay, S. Meier, J. R. Roche, and J. J. Loor. 2017. Far-off and close-up dry matter intake modulate indicators of immunometabolic adaptations to lactation in subcutaneous adipose tissue of pasture-based transition dairy cows. J. Dairy Sci. 100:2334-2350.

Vandesompele, J., K. De Preter, F. Pattyn, B. Poppe, N. Van Roy, A. De Paepe, and F. Speleman. 2002. Accurate normalization of real-time quantitative RT-PCR data by geometric averaging of multiple internal control genes. Genome Biol. 3:H0034.

von Soosten, D., U. Meyer, E. M. Weber, J. Rehage, G. Flachowsky, and S. Danicke. 2011. Effect of trans-10, cis-12 conjugated linoleic acid on performance, adipose depot weights, and liver weight in early-lactation dairy cows. J. Dairy Sci. 94:2859-2870.

Wildman, E., G. Jones, P. Wagner, R. Boman, H. Troutt, and T. Lesch. 1982. A dairy cow body condition scoring system and its relationship to selected production characteristics. J. Dairy Sci. 65:495-501. 